\title{
Towards Efficient Green Architecture and Sustainable Facades Using Novel Brick Design
}

\author{
Zaid A.O. Aldeek
}

Department of Architecture, Hijjawi Faculty for Engineering Technology, Yarmouk University, Irbid 21163, Jordan

Corresponding Author Email: zaid.d@yu.edu.jo

https://doi.org/10.18280/ijdne.150210

Received: 27 December 2019

Accepted: 18 March 2020

\section{Keywords:}

novel brick design, absorption of carbon oxides, green breathing facades, non-irrigated vertical vegetation, micro particulate absorption, climate change

\begin{abstract}
The most influential element in green architecture is the facade since it represents the major expression of architecture and separates the internal micro-climate and external environment. This paper focuses on the design of new types of interactive facades, developing new typologies, such as an interactive facade that aims to reduce air pollution among a system of facades that allows micro, non-irrigated vertical vegetation development, absorption, and fixing of micro particles through inspiration process. The interactive green facade uses special bricks designed to permit an inspiration and aspiration process caused by different temperature and humidity levels, which, in turn, promotes the growth of micro-vegetations. Both elements help to reduce air pollution and could be used separately or together. The facade obtained with this method introduces an innovative concept of green facades and helps to reduce carbon and other oxides that cause global warming. The scope of this research is to produce high performance facades that are conceptually based on simplified and advanced technologies.
\end{abstract}

\section{INTRODUCTION}

In architectural design, facades represent the major element of architectural expression. Engineers and architects make every effort to express their culture, artistic sense, and structural complexity. Earlier this century, the facade acquired new meanings and new functions with the arrival of new materials and new technologies. This paper introduces an innovation that can transform the traditional concept of the use of facades in architecture and building construction in general by addressing challenges such as air pollution. Facades could help to reduce air pollution as well as the energy consumption necessary for heating and cooling buildings.

The concept of the proposed green, non-irrigated or partially irrigated facades depends on the use of a special brick that allows for the development of green vegetation with a low growing process. This type of vegetation does not require complex maintenance or irrigation. Thus, it is easy to design complex green facades because green systems do not present complications at the level of implants or consumption. Secondly, this brick is designed in a manner that allows for an exchange of air between the brick and the environment, regardless of vegetation, which can help to fix parts of air pollution.

\section{RESEARCH MOTIVATIONS}

The design of interactive facades (in particular, those that are green) presents a target and challenge for many architects and designers with different motivations and considerations, such as artistic and poetic elements, performance, and comfort. It is possible to compare the famed Hanging Gardens of Babylon to the Milan Green Towers (see the literature review section). This paper aims (beside satisfying the general motivations cited before) to develop a system characterized by simplicity in realization that is totally sustainable. The concept presented in this research bio-mimetics nature with the goal of reducing air pollution and creating a new conceptual language in green architectural design.

\section{LECTURER REWIEW}

Green is a milestone for modern architecture. Difficulties to develop valid models are referred to the confused debate about green and sustainable architecture, a revision of traditional architecture and construction processes is needed. Rather than the complex artificial systems proposed by modern architecture, green architecture must involve an engineering system of architecture [1]. The debate on green architecture meets its sublimation when dealing with particularly tall buildings. Elements of complexity, such as sustainable irrigation, maintenance and costs, limit their diffusion. In some cases, vertical green architecture is the sum of vegetation disposed on vertical layers. Success in this field could be obtained through a new interactive facade design.

Green architecture requires a special approach to design, dealing with technical problems and requirements to provide a qualitative human environment and satisfy structural issues, such as strength, stability, durability [2]. These elements highlight the need to develop green architecture differently. The novel aspect of the research presented in this study limits the amount of related literature; the extant literature primarily focuses on traditional green facades or green architecture generally. New thinking logarithms, dealing with sustainability, could contribute actively to developing new technologies able to reduce carbon footprints and increase the efficiency of the interaction between environment and building [3]. Would evidence positions related to the debate 
on green architecture and facades without becoming a study of examples or case studies with finality to demonstrate the need to modify current methods of designing sustainable buildings generally.

The research highlights the potentiality of green facades to provide thermal control of building surfaces, presenting a balanced heat transmission in and out. The benefits are multiple in warm and cold seasons, improving comfort, as discussed largely in green architecture [4]. Vegetated facades have traditionally been used to offer multiple benefits, such as improving the quality of urban design and micro-climate. In past years, much attention has been paid to the design of vegetated facades, producing some examples in Europe and America, where experiments were characterized by the simple use of greening and did not present elements that can be considered innovative design [5].

The debate must include the definition of green facades to reduce confusion between the terms; living wall, vertical garden, and green facade define characteristics and design elements of each one [6]. The term "living wall" is a system of vegetation growing vertically on a physical internal or external wall, presenting many beneficial functions, such as balancing outdoor and indoor comfort, ecological value, biodiversity, insulation, improvement of air quality, mitigation of the urban heat island phenomenon, and better sensational impact on people [7]. While the term "hanging garden" indicates a vertical greening of a space like a terrace to create livable spaces and provide climatic mitigation between external and internal. This type of green architecture is very diffused in advanced countries. The main problems are elevated costs, elevated quantities of water necessary to maintain vegetation life, and the high carbon footprint caused from the heavy supports needed; these factors limit sustainability [8]. Green walls are a greening system used in building facades covered with vegetation, creating aesthetic value which can be maximized to give functional benefits [9]

Advanced research centers specialized in air pollution focus their efforts on two areas: The first is the use of nanomaterials and chemical reactions. This type of research begins in automobile industries, producing motors with low emissions and employing types of catalysts with success. Thus, the obtained success encourages research, extending it to other industries, particularly across the building sector to develop new technologies based on the use of chemical photocatalyzation. As an example, the latest use of ammonia capsules to treat escaping gases in diesel engines developed by Amminex Emissions Technology was based on the separation of molecules of nitrogen oxides, reducing emissions drastically [10]. Another example is the research conducted by Italcementi using titanium-oxide as a photo-catalyzer. In synthesis, the surface of building elements containing titanium-oxide react under the sun or artificial light, which ionizes nitrogen oxide and produces inert salts and oxygen [11]. The literature highlights how global research attention has focused on reducing emissions of nitrogen oxides, leaving the scenario opened as to how to reduce the carbon oxides emissions. Sustainable greening remains one of the most promising paths to valid contributions.

\section{DISCUSSION}

Conclusions from the literature review highlight the strong demand for vertical greening in contemporary architecture, particularly in advanced countries with different motivations; sensational elements arriving a satisfy technical requirements as thermal comfort inside and urban mitigation of micro clime. The main drawbacks of current vertical systems of greening are that they increase carbon footprints and require continued maintenance and abnormal quantities of water for irrigation. Although the current systems have good intentions, they do not produce the desired results. This research aims to overcome these issues with an innovative design that allows for sustainable light green and non-irrigated (or partially irrigated) facades, considering the facade as a skin that is sensitive to wind, light, rain, drought, snow, and so forth, and bio mimetics natural functions, such as breathing, carbon capturing, and water humidity control through multiple layers [12].

The use of green facades provides many benefits and poses matters to be resolved. The green facade as a building envelopment (as proposed in this article) improves its thermal performance in all seasons, through the mitigation of internal and external temperatures in hot seasons. In cold seasons, it works as thermal insulation. Irrigation and the high dead load of traditional green vertical architecture increase costs, limiting its diffusion, which prompts research into new, more suitable typologies.

The interaction of the green vertical facade with the environment is necessary to develop light greening, which condenses water vapor necessary for its irrigation together carbon oxides and pollutants. Examples of spontaneous undesired growth of some vegetation in building facades illustrate how facades could be a good environment to develop new methods of sustainable greening (See Figure 1). Primary vegetation, such as mosses, are becoming more frequently used in internal architecture (see, for example, the Moss Walls by Joe Zazzera and Pat Mahan [13]. This type of greening presents important innovations, promoting a type of greening that does not need much maintenance as moss does not wither away in poor conditions, but rather remains dormant until superior conditions are restored.

Challenges related to providing enough irrigation during summer days could be resolved by using vapor condensation from the atmosphere and integrating partial irrigation implants, which use water harvested from the rain and alternative sources, such as the condensation produced by air conditions.

This paper, based on data and experiments acquired by the author, develops a simple concept of a "green brick". This simple concept could be used to satisfy complicated issues. Additionally, the simplicity of the concept could make largescale production and diffusion possible.

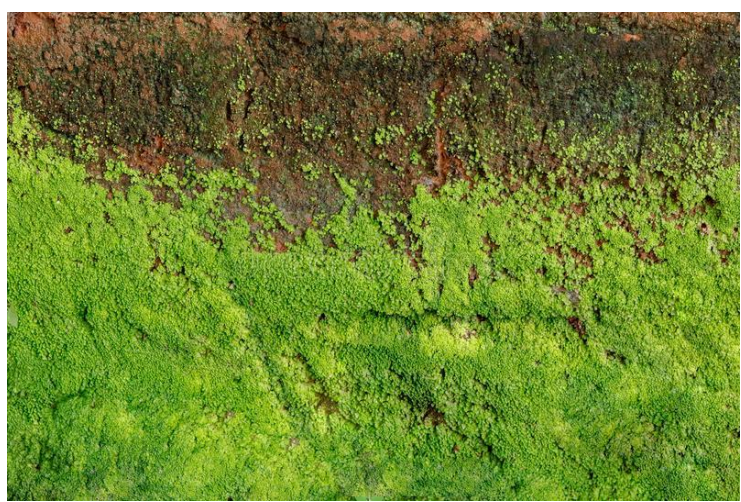

Figure 1. Spontaneous growth of primary vegetations (moss) on walls 


\section{THE PROPOSED GREEN AND NON-IRREGATED FACADE USING NOVEL BRICK'S DESIGN}

The novel brick combines two principles: The first is the continuous air exchange between the brick cavity and the environment caused by different pressures and temperatures, resulting in a natural respiration process. The second is the ability to have primary vegetation wherever water and sun radiation are present (see Figure 3). These processes can avenue independently or together.

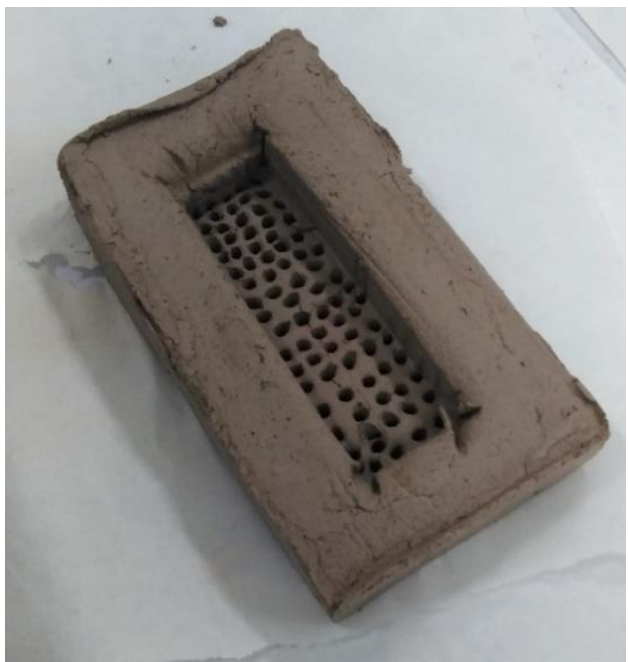

(a)

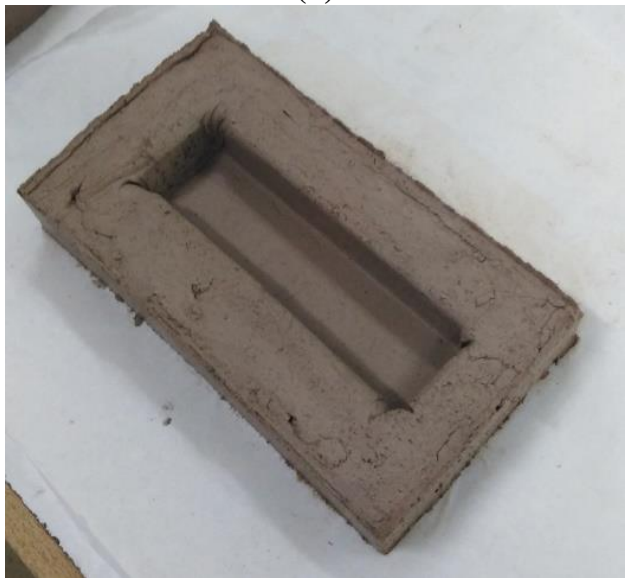

(b)

Figure 2. The realization of the novel brick for major simplicity is divided into two parts

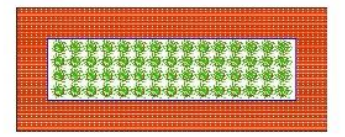

Novel Brick's Lateral view

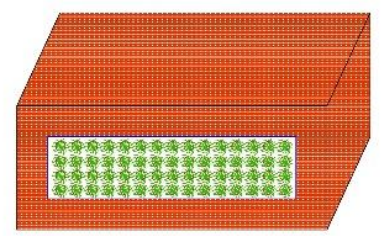

Novel Brick's Genral Aspect

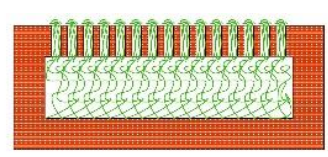

Novel Brick's Horizontal Section

Novel Brick's Vertical Section
Figure 3. The final aspect of the novel green brick: Vegetation grown in the cavity
As shown in Figure 2, the novel brick is a simple and ordinary brick that differs from traditional bricks in its design, while costs and construction methodology stay the same. The novel brick can be realized in many forms and materials that satisfy the desired scope. In this paper, we focus on the use of clay as a material because of its consolidated techniques of fabrication, low cost, availability, and durability. Clay is one of most important building materials, performance and quality when used in different parts of the building is demonstrated cross a large history and diffusion offers a promising building technology, able to respond to regional neediness to specific climatic conditions. The large diffusion of the clay use in different societies and periods permits us to propose it as a modern building material able to satisfy different technical issues. Durability, affordability and ecological characteristics pose its use as appropriate in advanced building construction sectors. Clay is diffused in all parts of the world; affordable, not toxic, recyclable, high energy parameters. Thus, we can consider clay able to be part of any building constructive process. Clay is obtained by the disintegration of some rock types, mixed with water becomes a malleable plastic form that permits the formation of many forms, especially in this paper with the proposed novel brick. Beside the facility of modelling of the clay, there are different performances as its capacity as humidity regulator, since it can absorb the moisture from the air and release it, clay blocks can absorb particulates contributing to the proposed novel brick targets. Figure 2 shows the external and internal cavity of the brick (the pores are connected to the internal cavity). During the exposition, the interactive facade builds up using the novel green brick exchanges for many reasons the nearest air, which is composed of a mixture of gas as water vapor, nitrogen, nitrogen oxides, carbon oxides and many other pollution elements. The hypothesis is that the novel brick will be able to fix some of the cited elements.

Figure 3 shows the final aspect and sections of the proposed brick. The dimensions of the brick can be altered as needed. The industrialization of the brick is divided into two phases: The first is the modelling and cooking of the clay. The second is to print grains of grass or micro algae within the brick cavity.

\subsection{Targets of the novel brick}

5.1.1 Exchanging abnormal quantities of mix gas that compose the atmosphere with finality to fix some pollution agents

Building facades that are fully immersed in their environment (internal and external) are useful in dealing with temperature, pressure, humidity, acidity, wind, and exposition to sun radiation. The behavior of facades themselves differs in relation to position and exposition. Building facades are a complex system in which each part reacts differently. The facade system has different conditions of temperature and humidity with respect to the environment. Thus, the hypothesis of having a continuous exchange of fluids with the environment is confirmed by physics. Figure 4 shows how the temperature of the facade is different from the nearest environment and will not be in equilibrium in any condition. Previous research demonstrates the efficiency of exchange principles between facades and environments. For instance, Italcementi industries developed a new cement using titanium oxides photocatalytic $\left(\mathrm{TiO}_{2}\right)$, creating a smog-eating material. The material captures air pollution when the facade meets light, then transforms the pollution to inert salts, and thus reduces smog levels in the environment [14]. 


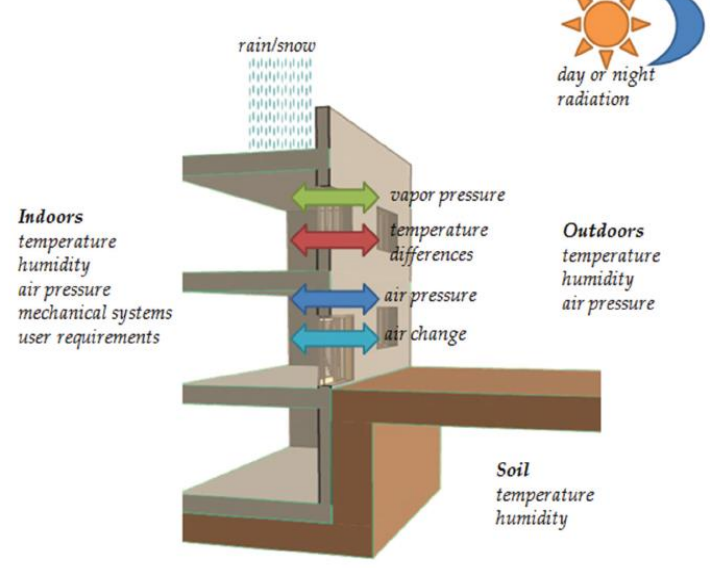

Figure 4. A section of the traditional facade, demonstrating the dynamicity between facade and environment [12]

5.1.2 Creation of a microenvironment within the cavity of the novel brick that incentivizes the growth of primary vegetation

Algae live in water environments naturally or in photobioreactors artificially. The first use of photo-bioreactors in a building facade was seen in the first "bio apartment building (2013), designed by Splitterwerk and Graz and by engineering firm Arup in Hamburg, Germany". An algae facade separates the indoors from the outdoors supplying direct thermal heating and indirect biomass for building uses [15].

The novel brick's cavity can be used to cultivate primary vegetations or algae, which will provide a green facade. Microvegetations do not need attention and do not constitute a load on a building system. The air humidity (integrated with an irrigation system) will guarantee their spontaneous growth (see Figure 5). Some types of algae grow like plants in nature (on rocks and wood). A variety of these types of algae grow without needing attention. Algae, cellular organisms considered the precursors to plants, are characterized by their ability to photosynthesize efficiently as vegetation removes $\mathrm{CO}_{2}$ from the surrounding environments, producing $\mathrm{O}_{2}$. The novel brick could also use types of grasses or other microvegetations, as we will see later.

The design of the proposed novel brick could be considered an environment that permits the growth of these types of algae. The principal difference between rock algae and aquatic algae that the first is directly exposed to sun radiation and the atmosphere, consuming carbon dioxide directly as in all vegetation.

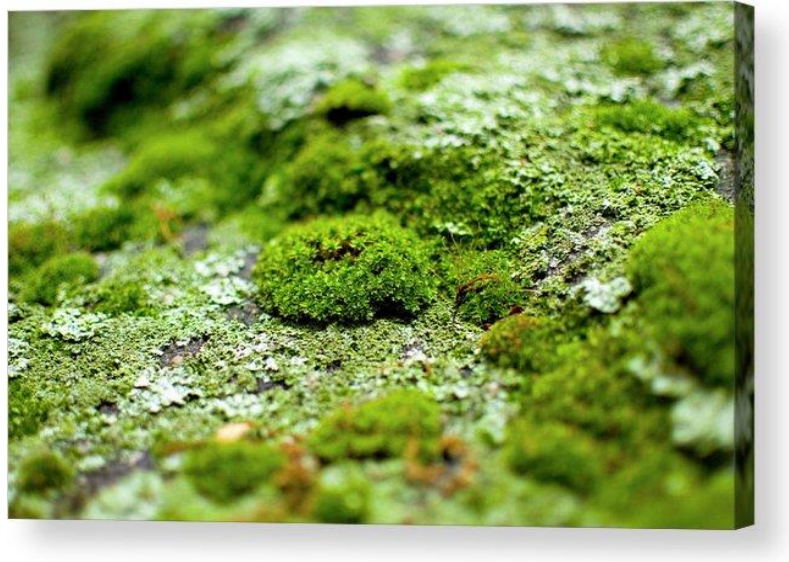

Figure 5. Micro algae moss growing on a rock

\section{NOVEL BRICK AND INTERACTIVE FACADE DESIGN}

\subsection{Novel brick design and working method}

The novel brick is designed in a manner that allows for continuous exchange between the external layer of the facade and the environment. Forms and materials used do not constitute the matter of the research; the preferred material is clay due to its durability, modelling ease, low cost, and natural compatibility. The novelty presented in this brick is that it allows greening elements to be transferred as part of the facade of a building. Green can also be printed in special bricks to be used normally as in all building construction processes. Thus, the simplification of the greening process incentivizes its diffusion

Figure 6 shows a section of the facade that is composed of novel bricks. The external environment and the cavities of the bricks are separated by a surface that contains many pores, with the aim of creating different environments (external and internal) with different relative temperatures and air pressures. Thermal capacity, bulk density, and the nature of the brick's surface produce several cycles of respiration and inspiration, absorbing some pollutants and humidity.

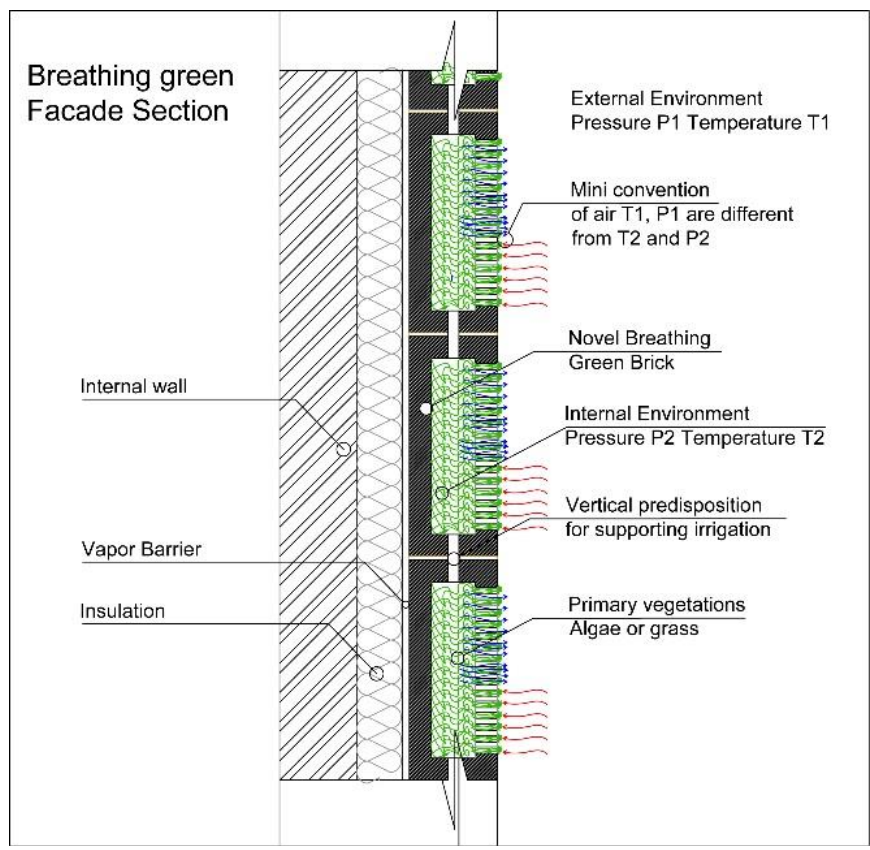

Figure 6. Breathing-green facade section

6.1.1 How the novel brick absorbs carbon oxides and other pollutants

The brick is thought to be a thermodynamic system, which means it has the capacity to exchange fluids with the external environment. The elements exchanged are the components of the atmosphere (carbon oxides, nitrogen, oxygen, humidity, sand, and others). It is possible that the brick works like a little heat pump. Even heat, air, and moisture across the building facade are phenomenal. Facade materials and design influence the thermal behavior of this unique phenomenon and can be controlled [16].

As stated previously, the brick is a thermodynamic system that is subject to temperature and pressure variations. Such variation grantee the continues input gas mixture. However, the smooth surface and the lightness of the brick verify the dew 
point on the brick cavity. This process grantee the solution of part of pollutants in the condensed water vapor, fixing some parts. Many pollutants have a high capacity to be solved in water, becoming inert and cleaned by successive rain.

6.1.2 How the novel brick develops primary or non-primary vegetation

In the conditions described above, the cavity of the novel brick is characterized as a humid environment with many organic and spontaneous inorganic depositions. This environment could be suitable for mini-vegetation (grasses) or primary vegetation, such as micro algae moss. Many types of grasses can resist to hard conditions and have a cycle life, which means the capacity to stand by awaiting the best conditions for growth. The result that we can plant special types of grasses within the proposed bricks suitable for many types of climates [17]. Nowadays, the need of industrial applications of the use of grasses produced many scientific innovations in this sector. Different vegetation types are produced to satisfy the demand of greening in architecture and in sports infrastructures, allowing us to have the suitable vegetation for every different climatic zone.

\subsection{Interactive facade's functioning}

Based on the novel brick's working process, we can design simple and complex breathing and green facades. The green facade is intended as a multilayer on which a cladding layer is directly applied to realize the proposed breathing-green facade. Use of the blocks to satisfy goals, simplify the building process, and increase potentialities is summarized in Table 1.

Table 1. Limitations and potentialities of the proposed breathing and green facades

\begin{tabular}{|c|c|c|c|}
\hline $\begin{array}{c}\text { Geographic } \\
\text { location }\end{array}$ & $\begin{array}{l}\text { Carbone } \\
\text { footprint } \\
\text { produced }\end{array}$ & $\begin{array}{c}\text { Structural } \\
\text { issues }\end{array}$ & $\begin{array}{c}\text { Irrigation } \\
\text { and } \\
\text { Sustainability }\end{array}$ \\
\hline $\begin{array}{l}\text { Suitable in } \\
\text { moderate } \\
\text { climates } \\
\text { and summer } \\
\text { rain zones. }\end{array}$ & $\begin{array}{l}\text { The industrial } \\
\text { process of } \\
\text { block } \\
\text { fabrication } \\
\text { does not } \\
\text { increase fuel } \\
\text { consumption. }\end{array}$ & $\begin{array}{l}\text { Do not add } \\
\text { an excessive } \\
\text { load. } \\
\text { Maintenance } \\
\text { not required. }\end{array}$ & $\begin{array}{l}\text { Irrigation is } \\
\text { supplied using } \\
\text { air humidity. } \\
\text { However, } \\
\text { some cases } \\
\text { use partial } \\
\text { irrigation. }\end{array}$ \\
\hline
\end{tabular}

Table 2. Performances of novel brick

\begin{tabular}{|c|c|c|c|}
\hline $\begin{array}{l}\text { Humidity } \\
\text { attraction }\end{array}$ & $\begin{array}{l}\text { Dew point } \\
\text { verification }\end{array}$ & $\begin{array}{l}\text { Thermal } \\
\text { capacity }\end{array}$ & $\begin{array}{c}\text { Resistance to } \\
\text { chemical } \\
\text { agents }\end{array}$ \\
\hline $\begin{array}{l}\text { High; seen it } \\
\text { the presence } \\
\text { of pores, } \\
\text { which } \\
\text { permit the } \\
\text { absorption } \\
\text { of water } \\
\text { vapour from } \\
\text { the nearest } \\
\text { atmosphere. }\end{array}$ & $\begin{array}{l}\text { High; the } \\
\text { reduced thermal } \\
\text { capacity caused } \\
\text { by the reduced } \\
\text { weight of the } \\
\text { brick incentivize } \\
\text { losing heat, } \\
\text { which is the first } \\
\text { condition of } \\
\text { verification of } \\
\text { the dew point; } \\
\text { the smooth } \\
\text { nature of brick's } \\
\text { surfaces is the } \\
\text { second } \\
\text { condition. }\end{array}$ & $\begin{array}{l}\text { Reduced; } \\
\text { cooked clay } \\
\text { bricks have } \\
\text { high } \\
\text { thermal } \\
\text { capacity } \\
\text { generally, } \\
\text { but if } \\
\text { designed to } \\
\text { have } \\
\text { reduced } \\
\text { weight, } \\
\text { acquire and } \\
\text { lose heat } \\
\text { easily. }\end{array}$ & $\begin{array}{l}\text { High; clay } \\
\text { bricks have a } \\
\text { very high } \\
\text { resistance to } \\
\text { chemical } \\
\text { agents and a } \\
\text { reduced } \\
\text { degradation } \\
\text { process, } \\
\text { resistant to } \\
\text { oxidant } \\
\text { agents and } \\
\text { physical } \\
\text { phenomena } \\
\text { such as } \\
\text { abrasion. }\end{array}$ \\
\hline
\end{tabular}

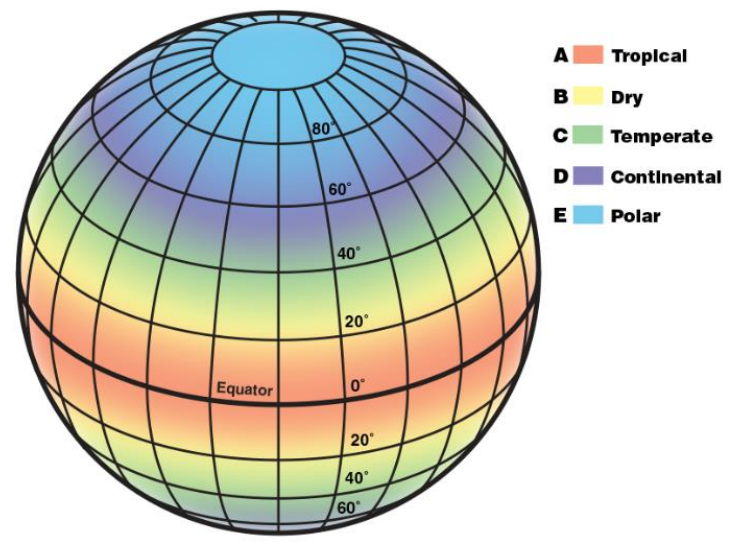

Figure 7. World climate zones distribution

The use of the proposed interactive facade has some limitations in arid climate zones where it is necessary to supply irrigation to maintain greening. Analyzing a map of climate zones (see Figure 7) reveals that the temperate zone covers a large part of the word. Major parts of Europe, the United States, China, and Japan belong to the moderate climate zone. These countries are directly interested in smog and pollution issues. Humidity and temperature in temperate zones permit the diffusion of irrigated vegetation in all seasons of the year. The physical form and materials used to produce the novel brick help create suitable conditions for both proposed vegetation types: micro algae moss and mini grasses.

Table 2 shows the performances of the novel brick, the brick produced from cooked clay has smooth surfaces with relative reduced thermal capacity (seen the bulk density related to the brick's volume). Surface and thermal capacity are the fundamental elements required to verify condensation of water vapor with decreasing temperature. The cycle of variations in temperature and humidity on the surface of the bricks used in the facade during day hours shows that it is possible one condensation at least once a day. While the temperature of the environment reaches a minimum near 6.00 a.m., the amount of water vapor is also greatest near $6.00 \mathrm{a} . \mathrm{m}$. The drastic decrease of temperature in the presence of high humidity guarantees the quantities of water necessary to maintain vegetation life.

The novel brick, which constitutes the breathing facade, is a smart technology because technology is included within its realization. The pores and equipment for vegetation are realized within the production process. Thus, the use of the proposed brick does not add complications to the building construction process. The industrialization of the product is the same one used in other types and does not increase costs or carbon footprint. In building realization, novel bricks present the same characteristics as traditional ones.

The use of the novel brick makes the use of green facades in high-rise buildings a reality; the technology can also easily be used in traditional ones. It can be used on internal walls and as a pattern of design. Facades realized with the proposed technology can satisfy important design requirements and reduce pollution

\subsection{Novel breathing and greened facade design}

Once the conditions that determine the success of the breathing process and maintain vegetation life have been defined, the design is reduced to technical matters that are easily resolvable. Patterns, forms, and types of vegetation do not play a crucial role in this stage. 
The simplicity and reduced weight of the novel brick permit a flexible ideation of many types of facades. The principle aim of this innovation is to design high-rise breathing and greened facades but meet applications with high potentiality in traditional buildings. Principally, as shown in Figure 6, the proposed facade works as anyone; some technical details are adopted as a self-irrigation system, possibility to obtain humidity saturation from the internal wall and from condition implants.

\section{CONCLUSIONS}

This research is based on the use of an innovative technology called novel brick, which can be used to design facades that can breathe and act sustainably, helping to incentivize the greening the surfaces of buildings. Buildings represent one of the major surfaces that are in contact with nature. Thus, green surfaces can contribute actively to reducing air pollution and to the effects of climate change.

The novel facade is based on the use of simple but advanced bricks where the targeted technology is within printed opening a new vision of building construction and green architecture. The simplicity of ideation, demonstration, and fabrication of this technology will allow it to be used and diffused largely.

\section{REFERENCES}

[1] Wang, Y., Zhang, W. (2011). Discussions on vegetal architecture, part I: Architecture as the science of the artificial. International Conference on Electric Technology and Civil Engineering (ICETCE), Lushan, China. https://doi.org/10.1109/ICETCE.2011.5775716

[2] Dorozhkina, E.A. (2018). Green architecture: Technical problems of greening buildings. IOP Conference Series: Materials Science and Engineering, International Conference on Construction, Architecture and Technosphere Safety (ICCATS 2018), South Ural State University, Russian Federation, 451: 26-28. https://doi.org/10.1088/1757-899X/451/1/012169

[3] Aldeek, Z.A.O. (2020). Green architecture and sustainability in the complex transformation of the built urban environment in Jordan. International Journal of Design \& Nature and Ecodynamics, 15(1): 113-120. https://doi.org/10.18280/ijdne.150115

[4] Sheweka, S.M., Mohamed, N.M. (2010). Green facades as a new sustainable approach towards climate change. Energy Procedia, 18: 507-520. https://doi.org/10.1016/j.egypro.2012.05.062

[5] Köhler. M. (2008). Green facades - a view back and some visions. Urban Ecosystems, 11(4): 423-436. https://doi.org/10.1007/s11252-008-0063-X

[6] Radić, M., Brković Dodig, M., Auer, T. (2019). Green facades and living walls-a review establishing the classification of construction types and mapping the benefits. $\quad$ Sustainability, $11(17)$ : 4579. https://doi.org/10.3390/su11174579

[7] Rakhshandehroo, M., Yusof, M., Johari, M., Arabi, R. (2015). Living wall (vertical greening): Benefits and threats. Applied Mechanics and Materials, 747: 16-19. https://doi.org/10.4028/www.scientific.net/AMM.747.1 6

[8] Sharma, P. (2016). Vertical Gardens - An Innovative Element of Green Building Technology. Corpus ID: 128001154.

[9] Manso, M., Castro-Gomes, J. (2015). Green wall systems: A review of their characteristics. Renewable and Sustainable Energy Reviews, 41: 863-871. https://doi.org/10.1016/j.rser.2014.07.203

[10] O'Donnell, B. (2016). Solid ammonia reduces Copenhagen bus emissions by $90 \%$. https://horizonmagazine.eu/article/ammonia-cuts-dieselemissions.html, accessed on Jan. 15, 2020

[11] Aleksandra, C. (2018). Photocatalytic self - cleaning facades in architectural design. Facta Universitatis, Series: Architecture and Civil Engineering, 16(3): 425436. https://doi.org/10.2298/FUACE180630019C

[12] Tokuç, A., Özkaban, F.F., Çakır, Ö.A. (2018). Biomimetic facade applications for a more sustainable future. Chapter 5. Open Access books. https://doi.org/10.5772/intechopen.73021

[13] Mihai, A. (2015). The Latest in Green Houses: Moss Walls. https://www.zmescience.com/ecology/greenliving/moss-walls/, accessed on Jan. 15, 2020.

[14] Italcementi Group TECHNICAL REPORT. (2008). The Photocatalytic Active Principle. http://www.fotocatalisis.org/assets/doc497.pdf, accessed on Jan. 15, 2020.

[15] SPLITTERWERK \& ARUP. (2014). The Algae House: About the First Building with A Bioreactor Facade. Hemmrich, Blaschitz, Wurm (eds.) SPLITTERWERK, Arup. Niggli Verlag, 96 pages, ISBN 978-3-7212-09075.

[16] Bomberg, M. (2013). Heat, air and moisture interactions. Frontiers of Architectural Research, 2(1): 116-119. https://www.scipedia.com/public/Bomberg_2013b

[17] Fernández, R., Reynolds, J. (2000). Potential growth and drought tolerance of eight desert grasses: Lack of a tradeoff? Oecologia, 123: 90-98. https://doi.org/10.1007/s004420050993 